\title{
Traction resistance of the combined machine plough
}

\author{
Dustmurod Chuyanov ${ }^{1 *}$, Golib Shodmonov ${ }^{1}$, Ibrat Ismailov ${ }^{2}$, Gayrat Ergashov ${ }^{1}$ and \\ Akramjon Sadikov ${ }^{1}$ \\ ${ }^{1}$ Karshi Engineering Economic Institute, Karshi, Uzbekistan \\ ${ }^{2}$ Russian State Agrarian University - Moscow Timiryazev Agricultural Academy, Moscow, Russia
}

\begin{abstract}
Subsoils are widely used on tillage and combination machines. The tiller of the combined machine for preparing the soil for sowing melons and gourds carries out strip loosening of the subsoil layers. The study aims to theoretically determine the traction resistance of a soil deepener of a combined machine for preparing the soil for sowing melons and gourds. The study uses the basic provisions of mathematics, theoretical mechanics, and agricultural mechanics. In studies, it is assumed that the destruction of the soil under the influence of the drill bit occurs by separation. The total traction resistance of the subsoiler was determined as the sum of the resistance of the rack and the bit. An analytical expression has been obtained to determine the traction resistance of a tilting machine with an inclined stand, depending on its design, technological parameters, and the physical and mechanical properties of the soil. As a result of theoretical studies, it was found that the traction resistance of the soil deepener is mainly influenced by its design parameters, the depth of soil cultivation, the physical and mechanical properties of the soil, and the speed of the machine.
\end{abstract}

\section{Introduction}

Soil deepeners designed for subsurface loosening of the soil are widely used on plows [111], combined tillage machines [12-34]. As a result of the subsurface loosening of the soil, the most favorable conditions are created to grow and develop plant roots. Irrigation water and the root system of plants easily penetrate into the loosened soil layers [1-2, 8, 22-24].

In combined machines, subsurface loosening is carried out simultaneously with the processing and preparation of the soil for sowing. The authors have developed a combined machine for soil preparation for sowing melons and gourds in one pass [6, 9, 16-17, 20]. For sub-plowing strip loosening of the soil, tillers with an inclined stand are installed on the machine bodies. The study aims to theoretically determine the traction resistance of a soil deepener of a combined machine for preparing the soil for sowing melons and gourds.

\footnotetext{
*Corresponding author: dchuyanov1@mail.ru
} 


\section{Methods}

On the combined machine proposed by the authors for preparing the soil for sowing melons and gourds, a soil deepener with an inclined stand 1 is installed, the chisel 2 of which is made in the form of a trihedral oblique wedge (Fig.1). The tiller stand is installed obliquely in the transverse-vertical plane at an angle $\beta_{1}$ and a longitudinal-vertical plane at an angle $\beta_{2}$.

The total traction resistance of the tiller installed on the body of the combined machine consists of the resistance of its rack 1 and chisel 2, that is

$$
R_{p x}=R_{s x}+R_{d x}
$$

where $R_{s x}$ and $R_{d x}$ is the thrust resistance of the rack and bit, respectively.

The traction resistance of the drill bit in the form of a triangular wedge can be expressed as follows

$$
R_{d x}=R_{1 x}+R_{2 x}+R_{3 x}+R_{4 x}
$$

where $R_{1 x}$ is the resistance to penetration of the bit blade into the soil; $R_{2 x}$ is the resistance of the soil to deformation (shear); $R_{3 x}$ is the resistance to the movement and rise of the soil layer along the working surface of the bit; $R_{4 x}$ is resistance (dynamic pressure of the formation), due to the force of inertia of the soil layer.

The $A B$ bit blade, located at an angle $\gamma$ to the direction of movement, perceives normal pressure $N_{1}$ from the soil side (Fig.2). Since the angle $\left(90^{\circ}-\gamma\right)$ is greater than the angle of friction of the soil against the chisel blade, the soil slides along the blade, which causes force.

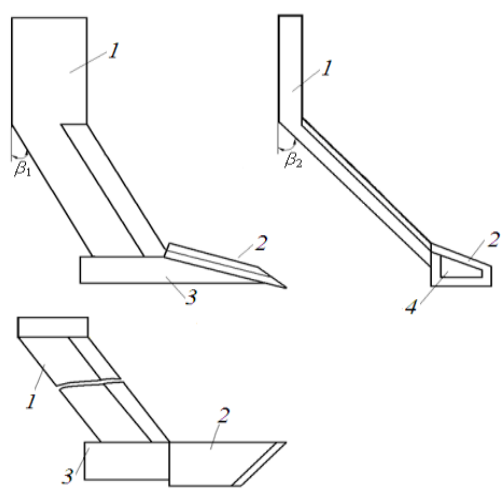

Fig. 1. A tiller with an inclined rack: 1 is rack; 2 are chisels; 3 is shoe

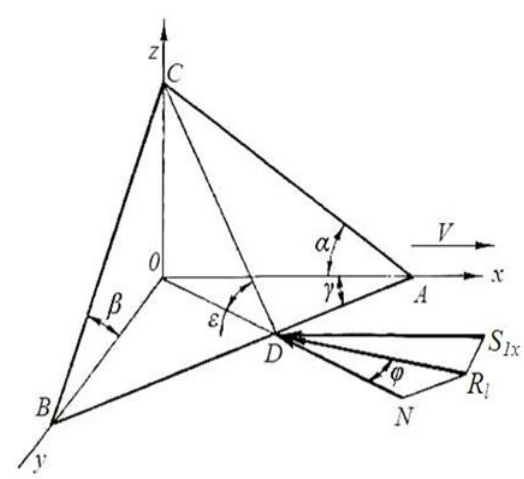

Fig. 2. Forces acting on the blade of an oblique triangular wedge

For this case, the soil resistance on the chisel blade is determined by the following expression

$$
R_{1 x}=\frac{b_{d}}{\sin \gamma} \delta \sigma_{o} \sqrt{1+f^{2}} \cos (\gamma+\varphi),
$$


where $\sigma_{o}$ is temporal resistance of the soil to crushing on the chisel blade, $\mathrm{Pa} ; \delta$ is chisel blade thickness, $\mathrm{m} ; b_{\partial}$ is chisel width, $\mathrm{m} ; f$ and $\varphi$ are the coefficient and angle of soil friction, respectively.

The displacement of the soil by the inclined plane of the wedge, located in the orthogonal section of the $C O D$ at an angle $\varepsilon$ to the horizon, occurs at a certain angle $\psi_{1}$ (Fig. 3) [34-36]. In conditions of blocked cutting, the shear area is determined by the following expression

$$
F_{1}=\frac{a_{p}\left[b_{d} \sin \psi+a_{p} \operatorname{tg}\left(\frac{\pi}{2}-\frac{\varphi_{2}}{2}\right) \sin \gamma\right]}{\sin \gamma \sin ^{2} \psi} .
$$

The shear force is

$$
S_{1}=\tau F_{1}=\tau \frac{a_{d}\left[b_{u} \sin \psi+a_{p} \operatorname{tg}\left(\frac{\pi}{2}-\frac{\varphi_{2}}{2}\right) \sin \gamma\right]}{\sin \gamma \sin ^{2} \psi},
$$

where $\tau$ is the net shear coefficient, $\mathrm{Pa} . S_{1}$ is force projection on the horizontal plane

$$
S_{1 g}=S_{1} \cos \psi_{1}
$$

$S_{1}$ is force projection on the $X$-axis

$$
S_{1 x}=S_{1} \cos \psi_{1} \sin \gamma
$$

In addition, the shear force $S_{1}$ causes a friction force $f N$ on the bit surface.

In addition, the shear force causes a friction force on the bit surface. Force $f N$ is directed at an angle $\alpha_{1}$ to the horizontal and is deflected from the longitudinal-vertical plane at an angle $\gamma_{1}$.

Here

$$
\begin{aligned}
& \alpha_{1}=\arcsin \operatorname{tg} \alpha \cos \varepsilon \\
& \gamma_{1}=\operatorname{arctg} \frac{(1-\cos \varepsilon) \operatorname{tg} \gamma}{1+\operatorname{tg}^{2} \gamma \cos \varepsilon}
\end{aligned}
$$

The component of the traction shear resistance $R_{2 \mathrm{x}}$ is equal to the sum of the projections of the forces $S_{1}$ and $f N$ [34-36]

$$
R_{2 x}=S_{1}\left[\cos \psi_{1} \sin \theta+f \sin \left(\varepsilon+\psi_{1}\right) \cos \alpha^{\prime} \cos \theta^{\prime}\right]
$$

Substituting the value of $S_{1}$ in (8) by expression (5), we have

$$
\begin{aligned}
& R_{2 x}=\frac{\tau a_{p}}{\sin \gamma \sin ^{2} \psi}\left[b_{d} \sin \psi+a_{p} \operatorname{tg}\left(\frac{\pi}{2}-\frac{\varphi_{2}}{2}\right) \sin \gamma\right]\left[\cos \psi_{1} \sin \gamma+\right. \\
& \left.+f \sin \left(\varepsilon+\psi_{1}\right) \cos \alpha_{1} \cos \theta_{1}\right] .
\end{aligned}
$$

Substituting the values of $\alpha_{1}$ and $\gamma_{1}$ in (9) by expressions (7) and (8), we obtain 


$$
\begin{aligned}
& R_{2 x}=\frac{\tau a_{p}}{\sin \gamma \sin ^{2} \psi}\left(b_{d} \sin \psi+a_{p} \operatorname{tg}\left(\frac{\pi}{2}-\frac{\varphi_{2}}{2}\right) \sin \gamma\right)\left[\cos \psi_{1} \sin \gamma+\right. \\
& \left.+f \sin \left(\varepsilon+\psi_{1}\right) \cos (\arcsin t g \alpha \cos \varepsilon) \cos \left(\operatorname{arctg} \frac{(1-\cos \varepsilon) \operatorname{tg} \gamma}{1+\operatorname{tg}^{2} \gamma \cos \varepsilon}\right)\right]
\end{aligned}
$$

The resistance to movement and rise of the soil layer along the working surface of the bit is also determined by the method of A.T.Vagin [34].

A.T.Vagin believes that when moving in the soil along the $X$ axis, the lower point of the layer $O$, when the wedge passes the path $O A$, will move to point $E$ along the straight line $A E E^{\prime}$. In this case, we neglect the magnitude of the formation compression. The rest of the points of the lower plane of the seam also move along straight lines parallel to $A E^{\prime}$ at an angle $\alpha_{1}$ to the horizon, deviating from the longitudinal-vertical plane $x O z$ by some angle $\gamma_{1}$. The traction resistance to the movement and rise of the soil layer along the working surface of the bit is determined by the following expression proposed by A.T.Vagin [34]

$$
R_{3 x}=G_{1}\left(\sin \alpha_{1}+f \cos \gamma\right) \cos \alpha_{1} \cos \gamma_{1}
$$

where $G_{1}$ is the weight of the soil on the inclined plane of the bit, $\mathrm{kN}$.

Soil weight

$$
G_{1}=\gamma a_{p} b_{d}\left(\frac{b_{d}}{2 \operatorname{tg} \gamma}+\frac{l_{z}}{\cos \alpha}\right)
$$

where $l_{z}$ is length of the quadrangular part of the bit (Fig. 4), m.

We can put the value of $G_{1}$ in the expression (13) according to (12)

$$
\begin{aligned}
& R_{3 x}=\gamma a_{p} b_{d}\left(\frac{b_{d}}{2 \operatorname{tg} \gamma}+\frac{l_{d}}{\cos \alpha}\right)(\operatorname{tg} \alpha \cos \varepsilon+f \cos \gamma) x \\
& x \sqrt{1-(\operatorname{tg} \alpha \cos \varepsilon)^{2}} \cos \left[\arg \operatorname{tg} \frac{(1-\cos \varepsilon) \operatorname{tg} \gamma}{1+\operatorname{tg}^{2} \gamma \cos \varepsilon}\right] .
\end{aligned}
$$

Traction resistance (dynamic pressure of the formation), due to the force of inertia of the soil layer when moving and lifting it along the working surface of the bit, is determined by the following formula [34]

$$
R_{4 x}=\frac{\gamma}{g} F_{2} v^{2} \sin \theta \cos \psi_{1}\left(1-i_{\max }\right)\left[\sin \theta \cos \psi_{1}+f \sin \left(\delta+\psi_{1}\right) \cos \alpha_{1} \cos \theta_{1}\right]
$$

where $F_{2}$ is the actual cross-sectional area of the $O M N B$, formation destroyed by the oblique wedge, that is, the bit; $\gamma$ is the volumetric weight of the soil; $i_{\max }$ is coefficient of maximum soil shrinkage. 


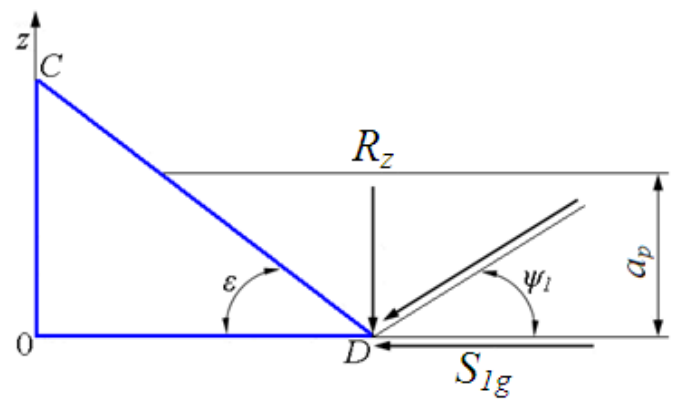

Fig. 3. Scheme of the soil layer displacement by an oblique wedge in a section orthogonal to the bit blade

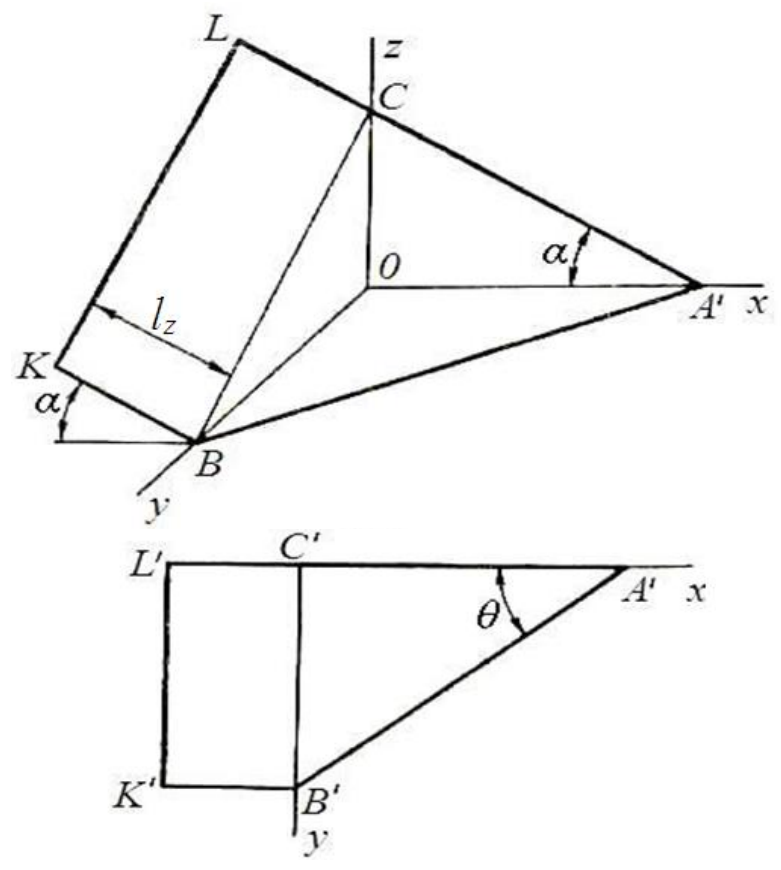

Fig. 4. Diagram of a bit in the form of an oblique wedge

From Fig. 5 we have

$$
F_{2}=\frac{1}{2} a_{p}\left(\frac{a_{p} \cos \gamma}{\operatorname{tg} \psi_{1}}+2 b_{d}\right)
$$

Substituting the value of $F_{2}$ in (13), we have

$$
\begin{aligned}
& R_{4 x}=\frac{\gamma}{g} \frac{1}{2} a_{p}\left(\frac{a_{p} \cos \gamma}{\operatorname{tg} \psi_{1}}+2 b_{d}\right) v^{2} \sin \theta \cos \psi_{1}\left(1-i_{\max }\right)\left[\sin \theta \cos \psi_{1}+\right. \\
& \left.+f \sin \left(\delta+\psi_{1}\right) \cos \alpha_{1} \cos \theta_{1}\right]
\end{aligned}
$$

Substituting the values of $\alpha_{1}$ and $\gamma_{1}$ in (6) by expressions (7) and (8), we obtain 


$$
\begin{aligned}
& R_{4 x}=\frac{\gamma}{g} \frac{1}{2} a_{p}\left(\frac{a_{p} \cos \gamma}{\operatorname{tg} \psi_{1}}+2 b_{d}\right) V^{2} \sin \gamma \cos \psi_{1}\left(1-i_{\max }\right)\left[\sin \gamma \cos \psi_{1}+\right. \\
& \left.+f \sin \left(\varepsilon+\psi_{1}\right) \cos (\arcsin t g \alpha \cos \varepsilon) \cos \operatorname{arctg} \frac{(1-\cos \varepsilon) \operatorname{tg} \gamma}{1+\operatorname{tg}^{2} \gamma \cos \varepsilon}\right]
\end{aligned}
$$

Substituting the values $R_{1 x}, R_{2 x}, R_{3 x}$, and $R_{4 x}$ according to expressions (1), (9), (11) and (17) in (18), we determine the traction resistance of the trench bit

$$
\begin{aligned}
& R_{u x}=\frac{b_{d}}{\sin \gamma} \delta \sigma_{o} \sqrt{1+f^{2}} \cos (\gamma+\varphi)+\frac{\tau a_{p}}{\sin \gamma \sin ^{2} \psi} \\
& {\left[b_{d} \sin \psi+a_{p} \operatorname{tg}\left(\frac{\pi}{2}-\frac{\varphi_{2}}{2}\right) \sin \gamma\right]\left[\cos \psi_{1} \sin \gamma+f \sin \left(\varepsilon+\psi_{1}\right) \cos (\arcsin t g \alpha \cos \varepsilon) x\right.} \\
& \left.x \cos \left(\operatorname{arctg} \frac{(1-\cos \varepsilon) \operatorname{tg} \gamma}{1+\operatorname{tg}^{2} \gamma \cos \varepsilon}\right)\right]+\gamma a_{p} b_{d}\left(\frac{b_{d}}{2 \operatorname{tg} \gamma}+\frac{l_{u}}{\cos \alpha}\right)(\operatorname{tg} \alpha \cos \varepsilon+f \cos \gamma) x \\
& x \sqrt{1-(\operatorname{tg} \alpha \cos \varepsilon)^{2}} \cos \left[\arg \operatorname{tg} \frac{(1-\cos \varepsilon) \operatorname{tg} \gamma}{1+\operatorname{tg}^{2} \gamma \cos \varepsilon}\right]+\frac{\gamma}{g} \frac{1}{2} a_{p}\left(\frac{a_{p} \cos \gamma}{\operatorname{tg} \psi_{1}}+\right. \\
& \left.+2 b_{d}\right) V^{2} \sin \gamma \cos \psi_{1}\left(1-i_{\max }\right)\left[\sin \gamma \cos \psi_{1}+\right. \\
& \left.+f \sin \left(\varepsilon+\psi_{1}\right) \cos (\arcsin \operatorname{tg} \alpha \cos \varepsilon) \cos \operatorname{arctg} \frac{(1-\cos \varepsilon) \operatorname{tg} \gamma}{1+\operatorname{tg}^{2} \gamma \cos \varepsilon}\right] .
\end{aligned}
$$

The resistance of the inclined part of the rack consists of the resistance of the blade and the chamfer of the working surface, the friction force arising on the side face of the rack

$$
R t_{x}=R_{l x}+R_{f x}+R_{f}
$$

The angle of inclination of the rack in the longitudinal-vertical plane $\beta_{I}=18^{0}$, while $\beta_{I} \leq \varphi$. In this case, cutting occurs with a longitudinal movement. For this case, the direction of the resultant force coincides with the direction of movement.

Where in

$$
\begin{aligned}
& R_{l n}=\sigma_{o} l_{n} \delta, R_{l x}=\sigma l_{n} \delta, \\
& R_{l x}=\sigma_{0} \delta \frac{l_{t}}{\cos \beta_{1}},
\end{aligned}
$$

here $l_{t}$ is rack blade length.

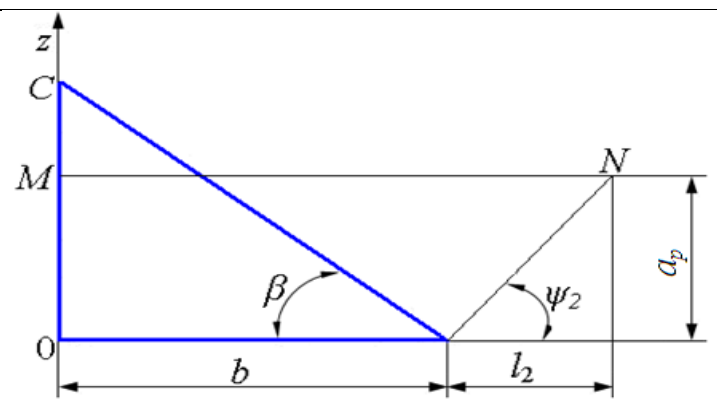

Fig. 5. Scheme of soil displacement by an oblique wedge in a longitudinal-vertical plane 


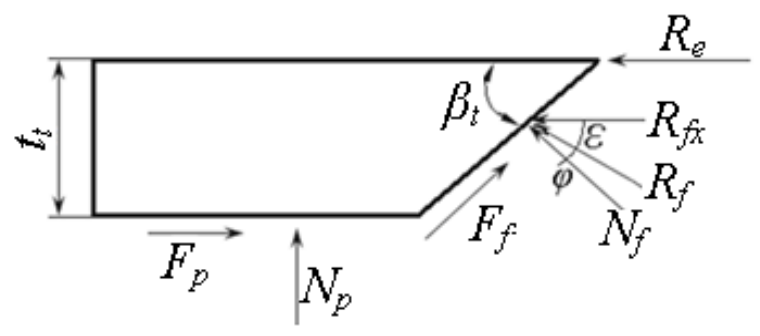

Fig. 6. Diagram of the forces acting from the soil on the rack

Rack blade length.

$$
l_{t}=\frac{a_{p}-h_{d}}{\cos \beta_{b}}
$$

where $h_{d}$ is the bit height, $\mathrm{m}$,

The equal effect of the elementary normal forces of soil resistance on the chamfer can be determined by the following formula

$$
N_{t n}=p_{t} l_{t} b_{f}=q l_{t} t_{t}^{2} / \sin \beta_{t}
$$

where $p_{t}$ is the specific pressure of the soil in the chamfer, $p_{t}=q t_{t} ; b_{t}$ is bevel width, $b_{f}=$ $t_{t} / \sin \beta_{t} ; \beta_{t}$ is the sharpening angle of the handle.
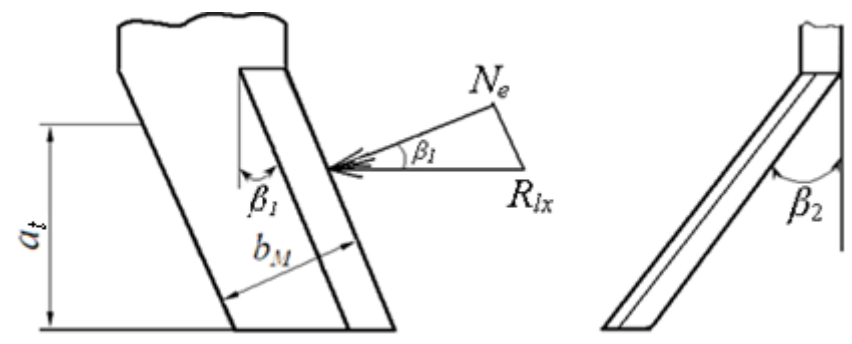

Fig. 7. Stance parameters and forces acting on it

The horizontal component of the resultant elementary normal forces of soil resistance to the chamfer of the rack can be determined by the following formula

$$
N_{f x}=p l_{t} b_{f}=q l_{t} t_{t}^{2}
$$

The resultant frictional forces arising on the side faces of the rack can be determined by the following expression

$$
F_{x}=N_{p} f=\frac{p f b_{t}}{\sin \beta_{1}}\left[2\left(a_{p}-h_{d}\right)-\frac{t_{t}}{\sin \beta_{2}}\right]
$$

where $p$ is specific soil pressure on the working surface of the inclined part of the rack.

Substituting the values of $R_{l x}, N_{f x}$, and $F_{x}$ according to (19), (22), and (24) in (17), we obtain 
the following expression for determining the thrust resistance of the rack

$$
R_{t x}=\sigma_{0} \delta \frac{l_{t}}{\cos \beta_{1}}+q l_{t} t_{t}^{2}+\frac{p f b_{t}}{\sin \beta_{1}}\left[2\left(a_{p}-h_{d}\right)-\frac{t_{t}}{\sin \beta_{1}}\right] .
$$

Substituting the values of $R_{d x}$ and $R_{s x}$ according to (19) and (25) into (17), we determine the total traction resistance of the subsoiler

$$
\begin{aligned}
& R_{c x}=\frac{b_{d}}{\sin \gamma} \delta \sigma_{o} \sqrt{1+f^{2}} \cos (\gamma+\varphi)+\frac{\tau a_{p}}{\sin \gamma \sin ^{2} \psi} x \\
& x\left[b_{d} \sin \psi+a_{p} \operatorname{tg}\left(\frac{\pi}{2}-\frac{\varphi_{2}}{2}\right) \sin \gamma\right]\left[\cos \psi_{1} \sin \gamma+f \sin \left(\varepsilon+\psi_{1}\right) \cos (\arcsin \operatorname{tg} \alpha \cos \varepsilon) x\right. \\
& \left.\cos \left(\operatorname{arctg} \frac{(1-\cos \varepsilon) \operatorname{tg} \gamma}{1+\operatorname{tg}^{2} \gamma \cos \varepsilon}\right)\right]+\gamma a_{p} b_{d}\left(\frac{b_{d}}{2 \operatorname{tg} \gamma}+\frac{l_{d}}{\cos \alpha}\right)(\operatorname{tg} \alpha \cos \varepsilon+f \cos \gamma) x \\
& x \sqrt{1-(\operatorname{tg} \alpha \cos \varepsilon)^{2}} \cos \left[\arg \operatorname{tg} \frac{(1-\cos \varepsilon) \operatorname{tg} \gamma}{1+\operatorname{tg}^{2} \gamma \cos \varepsilon}\right]+\frac{\gamma}{g} \frac{1}{2} a_{p}\left(\frac{a_{p} \cos \gamma}{\operatorname{tg} \psi_{1}}+\right. \\
& \left.+2 b_{d}\right) V^{2} \sin \gamma \cos \psi_{1}\left(1-i_{\max }\right)\left[\sin \gamma \cos \psi_{1}+\right. \\
& \left.+f \sin \left(\varepsilon+\psi_{1}\right) \cos (\arcsin t g \alpha \cos \varepsilon) \cos \operatorname{arctg} \frac{(1-\cos \varepsilon) \operatorname{tg} \gamma}{1+\operatorname{tg}^{2} \gamma \cos \varepsilon}\right]+ \\
& +\sigma_{0} \delta \frac{l_{t}}{\cos \beta_{\sigma}}+q l_{t} t_{t}^{2}+\frac{p f b_{t}}{\sin \beta_{1}}\left[2\left(a_{p}-h_{d}\right)-\frac{t_{t}}{\sin \beta_{2}}\right] .
\end{aligned}
$$

The analysis of the obtained expression shows that the traction resistance of the tiller of the combined machine depends on its parameters $\left(t_{t}, h_{d}, \alpha, \gamma, \beta_{l}, \beta_{2}, \delta\right)$, depth of tillage $\left(a_{p}\right)$, physical and mechanical properties of soil $\left(a_{p}\right)$, physical and mechanical properties of soil $\left(\sigma_{0}, \tau, \varphi_{1}, \varphi_{2}, \rho, W, q, f\right)$ and vehicle speed. Calculations by expression (26) at $\sigma_{o}=1,44 \cdot 10^{6} \mathrm{~Pa}, \tau=2 \cdot 10^{4} \mathrm{~Pa}, f=0,5774, \varphi_{1}=30^{0}, \varphi_{2}=40^{0}, \rho=1520 \mathrm{~kg} / \mathrm{m}^{3}, W=14 \%, \delta=0,002 \mathrm{~m}$; $b_{d}=0,05 \mathrm{~m}, t_{t}=0,015 \mathrm{~m}, h_{d}=0,008 \mathrm{~m}, l_{d}=0,14 \mathrm{~m}, q=1,5 \cdot 10^{7} \mathrm{~N} / \mathrm{m}^{3}, p=1,64 \cdot 10^{2} \mathrm{~Pa}, \alpha=18^{0}, \gamma=45^{0}$, $\beta_{1}=18^{0}, \beta_{2}=25^{0}, b_{t}=0,08 \mathrm{~m}, t_{t}=0,015$ and $a_{p}=0,15 \mathrm{~m}$ show that at vehicle speeds $2-2.5 \mathrm{~m} / \mathrm{s}$ the traction resistance of the tiller of the combined machine is $1710-1820 \mathrm{~N}$.

\section{Results and Discussion}

This paper presents the results of a series of calculations of the current field in the river bed during floods and low-water conditions.

Two-dimensional Saint-Venant's equations were solved numerically using an explicit finite-difference scheme described in [Ошибка! Источник ссылки не найден.]. То study the flow regime in the river channel, the following conditions were set: an initial water level in the area, a water flow rate at the entrance to the area, a water flow rate of water withdrawn from the river to the canal and the curve of the relationship between the flow rate and the water level at the exit from the area. After that, calculations were carried out until the time when the flow regime is stabilized, and the sum of the flow rate withdrawn from the river to the canal and the flow rate at the exit from the area will become equal to the flow rate of water at the entrance to the area.

The results of the initial calculations of the current field were carried out based on the available topographic data (Figure 1). 


\section{Conclusions}

1. Analytical relationships have been obtained to determine the soil resistance forces that arise when a soil deepener with an inclined stand is exposed to it.

2. It has been established that the traction resistance of the soil deepener depends on the parameters of the stand and chisel, the depth of the working body, the physical and mechanical properties of the soil, and the speed of the machine.

\section{References}

1. Mamatov, F.M., Eshdavlatov, E., Suyunov, A. The Shape of the Mixing Chamber of the Continuous Mixer // Jour of Adv Research in Dynamical \& Control Systems, Vol. 12, 07-Special Issue, (2020). DOI: 10.5373/JARDCS/V12SP7/20202318 ISSN 1943$023 \mathrm{X}$.

2. Mamatov F., Ergashev I., Ochilov S., Pardaev X. Traction Resistance of Soil Submersibility Type "Paraplau", Jour of Adv Research in Dynamical and Control Systems, Vol.12, 07-Special Issue, (2020). DOI: 10.5373/JARDCS/V12SP7/20202336 ISSN1943-023X.

3. Aldoshin N., Mamatov F., Ismailov I., Ergashov G. Development of combined tillage tool for melon cultivation, 19th international scientific conference engineering for rural development Proceedings, Jelgava, 20.-22.05.2020. Volume 19. ISSN 16915976. DOI:10.22616/ERDev.2020.19.TF175.

4. Umurzakov, U., Mirzaev, B., Mamatov, F., Ravshanov, H., Kurbanov, S. A rationale of broach-plow's parameters of the ridge-stepped ploughing of slopes // XII International Scientific Conference on Agricultural Machinery Industry IOP Conf. Series: Earth and Environmental Science 403(2019) 012163 IOP Publishing doi:10.1088/1755-1315/403/1/012163.

5. Mirzaev B., Mamatov, F., Chuyanov, D., Ravshanov X., Shodmonov, G., Tavashov, $\mathrm{R}$ and Fayzullayev, X. Combined machine for preparing soil for cropping of melons and gourds, XII International Scientific Conference on Agricultural Machinery Industry. doi.org/10.1088/1755-1315/403/1/012158.

6. Mirzaev, B., Mamatov, F., Ergashev, I., Ravshanov, H., Mirzaxodjaev, Sh., Kurbanov, Sh., Kodirov, U and Ergashev, G. Effect of fragmentation and pacing at spot ploughing on dry soils, E3S Web of Conferences 97. doi.org/10.1051/e3sconf/201913501065.

7. Mamatov, F., Mirzaev, B., Shoumarova, M., Berdimuratov, P., Khodzhaev, D. Comb former parameters for a cotton seeder// International Journal of Engineering and Advanced Technology (IJEAT) Volume-9, DOI: 10.35940/ijeat.A2932.109119

8. Mamatov, F., Mirzaev, B., Batirov, Z., Toshtemirov, S., Tursunov, O., Bobojonov, L. Justification of machine parameters for ridge forming with simultaneous application of fertilizers, IOP Conf. Series: Materials Science and Engineering 883(2020) 012165 IOP Publishing. doi:10.1088/1757-899X/883/1/012165.

9. Mirzaev, B., Mamatov, F., Avazov, I., Mardonov, S. Technologies and technical means for anti-erosion differentiated soil treatment system // E3S Web of Conferences. doi.org/10.1051/e3sconf/20199705036.

10. Aldoshin N., Didmanidze O., Mirzayev B., Mamatov F. Harvesting of mixed crops by axial rotary combines, Proceeding of $7^{\text {th }}$ International Conference on Trends in Agricultural Engineering 2019. $17^{\text {th }}-20^{\text {th }}$ Prague, Czech Republic, pp.20-26. September (2019).

11. Mirzaev B., Mamatov F., Aldoshin N and Amonov M. Anti-erosion two-stage tillage by ripper, Proceeding of 7 th International Conference on Trends in Agricultural 
Engineering 17th-20th. Prague, Czech Republic. - pp.391-396. September (2019).

12. Mirzaev, B., Мamatov, F., Ergashev, I., Islomov, Yo., Toshtemirov, B., Tursunov, O. Restoring degraded rangelands in Uzbekistan // Procedia Environmental Science, № 6. - pp 395-404. (2019).

13. Uzakov Z.U., Mamatov F.M., Begulov O. Implementation of object-oriented Programming technology in the one-dimensional oil displacement problem // International Conference on information Science and Communications Technologies: ICISCT 2019/0012008. Tashkent, Uzbekistan. INSPEC Accession Number: 19412491. DOI: 10.1109/ICISCT47635.2019.9012008.

14. Mamatov, F., Mirzaev, B., Berdimuratov, P., Turkmenov, Kh., Muratov, L., Eshchanova, G. The stability stroke of cotton seeder moulder // CONMECHYDRO 2020. IOP Conf. Series: Materials Science and Engineering 883 (2020) 012145 IOP Publishing. doi:10.1088/1757-899X/883/1/012145.

15. Mamatov, F., Mirzaev, B., Tursunov, O. A Justification of Broach-Plow's Parameters of the Ridge-Stepped Ploughing // E3S Web of Conferences 97, 05035 (2019). doi.org/10.1051/e3sconf/20199705035.

16. Ahmedov B.J., Mirzaev, B.S.,Mamatov, F.M., Khodzhaev, D.A., Julliev, M.K. Integrating of gis and gps for ionospheric perturbations in d- And f-layers using vlf receiver, InterCarto, InterGIS 26, - c. 547-560. DOI: 10.35595/2414-9179-2020-1-26547-560.

17. Mamatov, F., Mirzaev, B., Tursunov, O., Ochilov, S and Chorieva, D. Relief, physicomechanical and technological properties of soil in the cotton growing area // ICECAE 2020. IOP Conf. Series: Earth and Environmental Science 614(2020) 012169. IOP Publishing. doi:10.1088/1755-1315/614/1/012169.

18. Shamsutdinov, Z., Ubaydullaev, Sh., Shamsutdinov, N., Mirzaev, B., Mamatov, F., and Chorshabiyev, N. The concept of the phytogenic field: theory, research experience and practical significance // ICECAE 2020. IOP Conf. Series: Earth and Environmental Science 614(2020) 012164. IOP Publishing. doi:10.1088/17551315/614/1/012164.

19. Umurzakov, U., Mamatov, F., Aldoshin, N., and Mirzaev, B. Exploration of tillage technologies in the Republic of Uzbekistan // ICECAE 2020 IOP Conf. Series: Earth and Environmental Science 614(2020) 012168. IOP Publishing. doi:10.1088/17551315/614/1/012168.

20. Mamatov, F., Aldoshin, N., Mirzaev, B., Ravshanov, H., Kurbanov, Sh and Rashidov, N. Development of a frontal plow for smooth, furless plowing with cutoffs, IOP Conf. Series: Materials Science and Engineering 1030 (2021) 012135 IOP Publishing. doi:10.1088/1757-899X/1030/1/012135.

21. Mamatov, F., Mirzaev, B., Mirzahodzhaev, Sh., Uzakov, Z and Choriyeva, D. Development of a front plow with active and passive working bodies, IOP Conf. Series: Materials Science and Engineering 1030 (2021) 012164. IOP Publishing. doi:10.1088/1757-899X/1030/1/012164.

22. Mamato, F.M., Eshdavlatov, E., Suyuno, A. Continuous Feed Mixer Performance, Journal of Advanced Research in Dynamical and Control Systems (JARDCS). Volume-12, 07-Spesia1 Issue, 2020. DOI: 10.5373/JARDCS/V12SP7/20202343. ISSN 1943-023X.

23. Mamatov, F., Ergashev, I., Mirzaev, B., Pardaev, X., Chorieva, D. Research of the Penetration Process of the Frontal Plow // 2nd Bukittinggi International Conference on Education (BICED) 2020. Journal of Physics: Conference Series 1779 (2021) 012002. IOP Publishing. doi:10.1088/1742-6596/1779/1/012002.

24. Kodirov, U., Aldoshin, N., Ubaydullayev, Sh., Sharipov, E., Muqimov, Z and Tulaganov, B. The soil preparation machine for seeding potatoes on comb // 
CONMECHYDRO - 2020 IOP Conf. Series: Materials Science and Engineering 883(2020) 012143 IOP Publishing doi:10.1088/1757-899X/883/1/012143.

25. Ravshanov, Kh., Fayzullaev, Kh., Ismoilov, I., Irgashev, D., Mamatov, S. The machine for the preparation of the soil in sowing of plow crops under film // CONMECHYDRO - 2020 IOP Conf. Series: Materials Science and Engineering 883(2020) 012138 IOP Publishing doi:10.1088/1757-899X/883/1/012138.

26. Ravshanov, H., Babajanov, L., Kuziev, Sh., Rashidov, N., Kurbanov, Sh. Plough hitch parameters for smooth tails// CONMECHYDRO - 2020 IOP Conf. Series: Materials Science and Engineering 883(2020) 012139 IOP Publishing doi:10.1088/1757899X/883/1/012139.

27. Chuyanov, D., Shodmonov, G.,Avazov, I., Rashidov, N, Ochilov, S. Soil preparation machine parameters for the cultivation of cucurbitaceous crops // CONMECHYDRO - 2020 IOP Conf. Series: Materials Science and Engineering 883(2020) 012139 IOP Publishing doi:10.1088/1757-899X/883/1/012122.

28. Mamatov F.M., Mirzaev B.S., Avazov I.J., Mardonov Sh.X. K voprosu jenergosberegajushhej potivojerozionnoj differencirovannoj sistemy obrabotki pochvy [On the issue of energy-saving anti-erosion differentiated soil treatment system]// Innovacii v sel'skom hozjajstve [Innovations in agriculture].- № 3(18). - P.58-63. Moskva, (2016).

29. Mirzaev B.S., Mamatov F.M. Protivojerozionnaja tehnologija grebnisto-stupenchatoj vspashki i plug dlja ee osushhestvlenija [Anti-erosion technology of comb-stepping plowing and plow for its implementation]// Prirodoobustrojstvo [Environmental Engineering].- №2. - pp.81-84. Moskva, (2015).

30. Mamatov F.M., Mirzaev B.S., Avazov I.J. Agrotehnicheskie osnovy sozdanija protivojerozionnyh vlagosberegajushhih tehnicheskih sredstv obrabotki pochvy $\mathrm{v}$ uslovijah Uzbekistana [Agrotechnical foundations for the creation of anti-erosion water-saving technical equipment for soil cultivation in Uzbekistan]// Prirodoobustrojstvo [Environmental Engineering].- № 4. - P.86-88. Moskva, (2014).

31. Lobachevskiy Ja. P., MamatovF.M., Ergashev I.T.Frontal'nyj plug dlja hlopkovodstva [Frontal plow for cotton growing] // Hlopok [Cotton].- № 6. - pp.35-37. Moskva, (1991).

32. Mamatov F, Mirzaev B. Erosion preventive technology of crested ladder-shaped tillage and plow design // European Applied Sciences. Stuttgart Germany, (2014).

33. Mamatov F, Chujanov D, Mirzaev B, Jergashev G. Agregat dlja predposevnoj obrabotki pochvy // - Sel'skij mehanizator, (2011).

34. Vagin A 1977 Mechanization of soil protection from water erosionin the Nonchernozem strip (Kolos)

35. Fayzullayev, Kh, Mamatov, S, Radjabov, M, Sharipov, Sh, Tavashov, R and Nurmanova, M. The quality of loosening the soil with subsoilers of the combined machine // IPICSE 2020. IOP Conf. Series: Materials Science and Engineering $1030 \quad$ (2021) 012171.IOP Publishing. doi:10.1088/1757899X/1030/1/012171.

36. Temirov, I, Ravshanov, Kh, Fayzullaev, Kh, Ubaydullaev, Sh and Kodirov, U. Development of a machine for preparing the soil for sowing melons under the film // IPICSE 2020. IOP Conf. Series: Materials Science and Engineering 1030 (2021) 012169. IOP Publishing. doi:10.1088/1757-899X/1030/1/012169. 